\title{
Enhanced Efficiency of Thiourea Catalysts by External Brønsted Acids in the
}

\section{Friedel-Crafts Alkylation of Indoles}

\author{
Eugenia Marqués-López, ${ }^{[a]}$ Ana Alcaine, ${ }^{[a]}$ Tomás Tejero ${ }^{[a]}$ and Raquel P. Herrera ${ }^{*[a],[b]}$
}

Dedicated to the Women in Chemistry in the 100th anniversary of the Nobel Prize being awarded to Marie Curie

Keywords: Friedel-Crafts / Indole / Thiourea / Brønsted acid / Nitroalkene

\begin{abstract}
A novel study of external Brønsted acid-assisted thiourea catalysts in the asymmetric Friedel-Crafts alkylation of indoles with nitroalkenes is reported. The final 3 -substituted indoles derivatives are synthesized with better results by cooperative effect between chiral thiourea and a Brønsted acid additive (1a·HA), than those obtained with sole thiourea catalyst 1a.

[a] Laboratorio de Síntesis Asimétrica, Departamento de Química Orgánica. Instituto de Síntesis Química y Catálisis Homogénea (ISQCH), CSIC-Universidad de Zaragoza. E-50009 Zaragoza, Aragón, Spain

Fax: +34 976762075

E-mail: raquelph@unizar.es

[b] ARAID, Fundación Aragón I+D, E-50004 Zaragoza, Spain Supporting Information for this article is available on the WWW under http://www.eurjoc.org/ or from the author
\end{abstract}

The effect of diverse catalysts, different acid additives, solvents and temperatures in the reaction is also explored. The high reactivity and selectivity of the reaction is presumptively attributed to an appropriate assembly between the Brønsted acid and the thiourea structure, affording a more acid and rigid catalytic complex.

\section{Introduction}

In the last decades Friedel-Crafts alkylation reaction ${ }^{[1]}$ has attracted much attention for the formation of new carbon-carbon bonds becoming a powerful tool in organic synthesis. In this field great efforts have been paid to develop new catalytic enantioselective variants. ${ }^{[2,3]}$ In this context the addition of indole derivatives to electron-deficient olefins enables direct access to 3substituted indole analogues with potential applications, since indole framework has been identified in a great range of natural and unnatural products and medicinal agents with interesting biological activities. ${ }^{[4]}$ Therefore the preparation of products with this privileged structural motif is nowadays a significant aim of investigation and the discovery of new catalytic enantioselective procedures is still an important challenge. Although this area of research has been more extensively explored using metal catalysis, ${ }^{[2]}$ important organocatalytic enantioselective examples have been also reported. ${ }^{[3]}$ Among the efficient explored electrophiles, nitroalkenes are one of the most attractive Michael acceptors in organic synthesis ${ }^{[5]}$ due to their versatility to be readily transformed into a large range of different functionalities. ${ }^{[6]}$ Nevertheless and in spite of their importance, the organocatalytic version of this process using nitroolefins remains scarcely explored. ${ }^{[7,8]}$

Recently, chiral thioureas have been shown to be versatile and efficient organocatalysts in many organic transformations. ${ }^{[9]}$ In this context, during our ongoing studies on organocatalysis we have centered part of our research interest on the application of thiourea catalysts, ${ }^{[7 a, 8 a, 10]}$ for the discovery of new asymmetric procedures. Nowadays and in this area, efforts are being devoted in the development of more reactive structures in order to overcome some drawbacks, such as high catalyst loading and low turnover rate.

A recent study revealed that both the reaction rate and the enantioselectivity were correlated to catalyst acidity and it could be efficiently used for the modulation of catalyst structure in hydrogen-bond-catalyzed enantioselective reactions. ${ }^{[1]}$ Founded on this idea, other authors have designed new more efficient catalysts introducing internal acidic elements, ${ }^{[7 \mathrm{~d}, 12]}$ different to the frequently used 3,5-bis- $\mathrm{CF}_{3}$-phenyl group, in the (thio)urea skeleton (Figure 1).

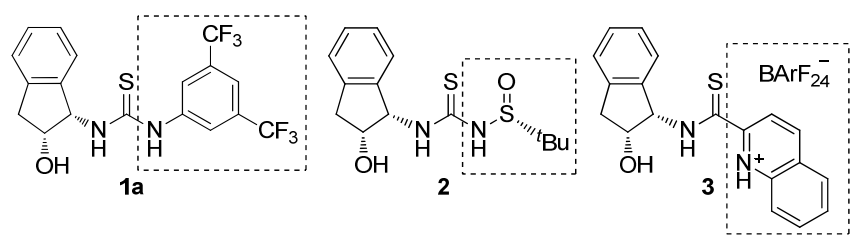

Figure 1. Representative examples of efficient thiourea catalysts.

We envisioned that higher enantioselectivity and reactivity might also be achieved using a suitable and tunable external Brønsted acid additive (HA) with a chiral thiourea catalyst if an appropriate assembly is accomplished between both. ${ }^{[13]}$ In this communication, we wish to report our preliminary results concerning this alternative approach of cooperative effect between Brønsted acid additives and chiral thiourea organocatalysts, which may lead to the development of a novel activity pattern as a new promising concept (Figure 2).<smiles>[R]NC(=S)Nc1cc(C(F)(F)F)cc(C(F)(F)F)c1</smiles><smiles>[R]NC(=S)Nc1cc(C([Y9])([R])F)cc(C(F)(F)F)c1</smiles>

Figure 2. New concept explored. Brønsted acid assisted thiourea organocatalysts. 


\section{Results and Discussion}

With the aim of increasing the acidity of chiral thioureas as more efficient catalysts, we thought that it was easier to control and modulate the catalyst acidity using an external additive than to modify the thiourea skeleton. The use of a carefully chosen acidic or basic additive has been more extensively studied in aminocatalysis, ${ }^{[14]}$ however it has been less considered in the field of (thio)urea catalysts, and in these few cases the thiourea was the additive in the catalytic system enhancing the activity of the corresponding acid catalyst. ${ }^{[15]}$ In order to evaluate the potential of this idea, we started our investigation exploring the reactivity of thiourea 1a with (L)-mandelic acid in a comparative study in the Friedel-Crafts alkylation reaction described in Scheme 1.



Scheme 1. (L)-Mandelic acid assisted thiourea 1a.

To our surprise the enantioselectivity for final adduct 6aa in presence of both (L)-mandelic acid and catalyst 1a was quite superior $(70 \%$ ee) to that obtained in absence of acid ( $38 \%$ ee). It is also remarkable that the reaction in presence of $(\mathrm{L})$-mandelic acid as the sole catalyst leads to a racemic mixture, being the synergic effect between both species higher than the effect promoted by each one separately. This initial promising result encouraged us to examine this significant reaction more extensively by exploring other suitable acids and indole derivatives (Table 1).

Table 1. Screening of the cooperative effect 1a $\mathbf{H A} .^{[a]}$

\begin{tabular}{|c|c|c|c|c|c|}
\hline \multicolumn{2}{|c|}{$\begin{array}{l}4 a\left(R^{1}, R^{2}=H\right) \\
4 b\left(R^{1}=H, R^{2}=M e\right) \\
4 c\left(R^{1}=M e, R^{2}=H\right)\end{array}$} & $\begin{array}{r}\begin{array}{r}1 \mathbf{a} \\
\text { Acid add }\end{array} \\
\mathrm{Cr}\end{array}$ & $\begin{array}{l}\mathrm{mol} \%) \\
\mathrm{e}(20 \mathrm{~mol} \\
\mathrm{d}_{2}, \text { r.t. }\end{array}$ & & $\begin{array}{l}\mathrm{R}^{1} \\
\mathrm{ca}\end{array}$ \\
\hline Entry & Acid (HA) & Indole & $\begin{array}{l}\text { Time } \\
\text { (days) }\end{array}$ & $\begin{array}{l}\text { Yield }^{[\mathrm{b}]} \\
(\%)\end{array}$ & $\begin{array}{l}\text { ee } \\
(\%)^{[c]}\end{array}$ \\
\hline 1 & (D)-Mandelic acid & $4 a$ & 4 & 79 & 70 \\
\hline 2 & $( \pm)$-Mandelic acid & $4 a$ & 4 & 83 & 70 \\
\hline 3 & $(R)-\mathrm{PhCH}(\mathrm{OMe}) \mathrm{CO}_{2} \mathrm{H}$ & $4 a$ & 4 & 71 & 71 \\
\hline 4 & $\mathrm{PhCH}_{2} \mathrm{CO}_{2} \mathrm{H}$ & $4 a$ & 4 & 65 & 58 \\
\hline 5 & $\mathrm{PhCO}_{2} \mathrm{H}$ & $4 a$ & 3 & 47 & 58 \\
\hline 6 & 2-Chloronicotinic acid & $4 a$ & 3 & 39 & 44 \\
\hline $7^{[\mathrm{d}]}$ & - & $4 b$ & 3 & 94 & 20 \\
\hline 8 & (L)-Mandelic acid & $4 b$ & 3 & 95 & 38 \\
\hline 9 & (D)-Mandelic acid & $4 \mathbf{b}$ & 3 & 95 & 38 \\
\hline $10^{[\mathrm{d}]}$ & - & 4c & 4 & 58 & $\operatorname{Rac}^{[\mathrm{e}]}$ \\
\hline 11 & (L)-Mandelic acid & 4c & 5 & 71 & $\operatorname{Rac}^{[\mathrm{e}]}$ \\
\hline 12 & (D)-Mandelic acid & $4 c$ & 5 & 70 & $\operatorname{Rac}^{[\mathrm{e}]}$ \\
\hline 13 & $\mathrm{CH}_{3} \mathrm{CO}_{2} \mathrm{H}$ & $4 a$ & 4 & 90 & 65 \\
\hline 14 & $\mathrm{CH}_{2} \mathrm{ClCO}_{2} \mathrm{H}$ & $4 a$ & 4 & 69 & 70 \\
\hline
\end{tabular}

4a

96

[a] Experimental conditions: To a mixture of catalyst 1a $(0.02 \mathrm{mmol})$, acid additive $(0.02 \mathrm{mmol})$ and nitroalkene $5 \mathbf{a}(0.1 \mathrm{mmol})$, first indole $4 \mathbf{a}-\mathbf{c}(0.15$ mmol $)$ and then $\mathrm{CH}_{2} \mathrm{Cl}_{2}(500 \mu \mathrm{L})$ were further added, in a test tube at room temperature. After the reaction time, adducts 6 were isolated by flash chromatography. [b] Isolated yield. [c] Determined by chiral HPLC analysis (see Supporting Information). [d] Reaction performed in absence of Brønsted acid. [e] Racemic mixture.

We first tested (D)- and ( \pm )-mandelic acid (entries 1 and 2) in order to study the match/mismatch effect and the same results than with the enantiomeric (L)-form (Scheme 1) were achieved. Interestingly the sense of the stereoselection was the same as that when thiourea 1a was the sole catalyst. This fact shows that chirality is preferentially governed by catalyst $\mathbf{1 a}$ and this outcome prompted us to think that the acid is activating the thiourea moiety rather than assembling by itself some of the reagents into the transition state. In such a case the stereochemistry in the acid might be determinant for the sign of the final enantiomer. On the other hand, catalyst complex 1a·HA was significantly less effective when indole derivatives $\mathbf{4 b}$ and $\mathbf{4 c}$ were also considered (entries 7 12). It is noteworthy that better enantioselectivities were also achieved with 2-methylindole (4b) (entry 8 and 9) compared with those obtained in absence of acid (entry 7). However with $N$ methylindole $4 \mathrm{c}$ the catalytic system afforded a racemic mixture with or without the presence of acid (entries 10-12). It suggests that the acid is just able to improve the results when thiourea catalyst renders final non-racemic mixtures. Diverse additives with different steric hindrance and acidic strengths were then explored. Although the data do not display a clear correlation with steric factors of the acid structures (entries 1-6 and 13-15), the acidity could affect the enantioselectivity and the reactivity of the process. In this respect, with a stronger acid, acid catalyzed reaction could compete against to the 1a·HA promoted one (entry 15). Even if the presence of $\mathrm{OH}$ group in mandelic acid seemed important for the enantioselectivity of the process (compared entry 1 and 3 ) similar and promising results were also obtained with $(R)$ $\mathrm{PhCH}(\mathrm{OMe}) \mathrm{CO}_{2} \mathrm{H}$ (entry 4) and $\mathrm{CH}_{2} \mathrm{ClCO}_{2} \mathrm{H}$ (entry 14). Our attention next turned to explore different synthesized thiourea catalysts $\mathbf{1 b}$-g under the same reaction conditions towards a better understanding of both catalyst mode of action and origin of the enantioselectivity in this process. To this purpose, different structural parameters were varied (Figure 3, Table 2).

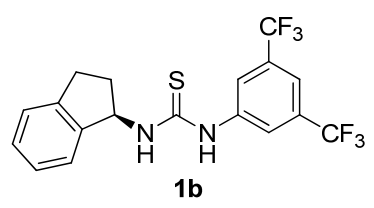<smiles>OC1Cc2ccccc2[C@H]1NC(=S)Nc1cc(C(F)(F)F)cc(C(F)(F)F)c1</smiles><smiles>OC1Cc2ccccc2C1NC(=S)Nc1cc(F)cc(F)c1</smiles><smiles>OC1Cc2ccccc2C1NC(=S)Nc1c(F)c(F)c(F)c(F)c1F</smiles><smiles>FC(F)(F)c1cc(NC(=S)Nc2ccc3ccccc3c2-c2c(NC(=S)Nc3cc(C(F)(F)F)cc(C(F)(F)F)c3)ccc3ccccc23)cc(C(F)(F)F)c1</smiles><smiles>Oc1ccc2ccccc2c1-c1c(NC(=S)Nc2cc(C(F)(F)F)cc(C(F)(F)F)c2)ccc2ccccc12</smiles>

Figure 3. Chiral thioureas tested $\mathbf{1 b}-\mathbf{1 g}$. 
Table 2. Screening of catalytic complexes $\mathbf{1 b}-\mathbf{g} \cdot \mathbf{H A} .^{[a]}$

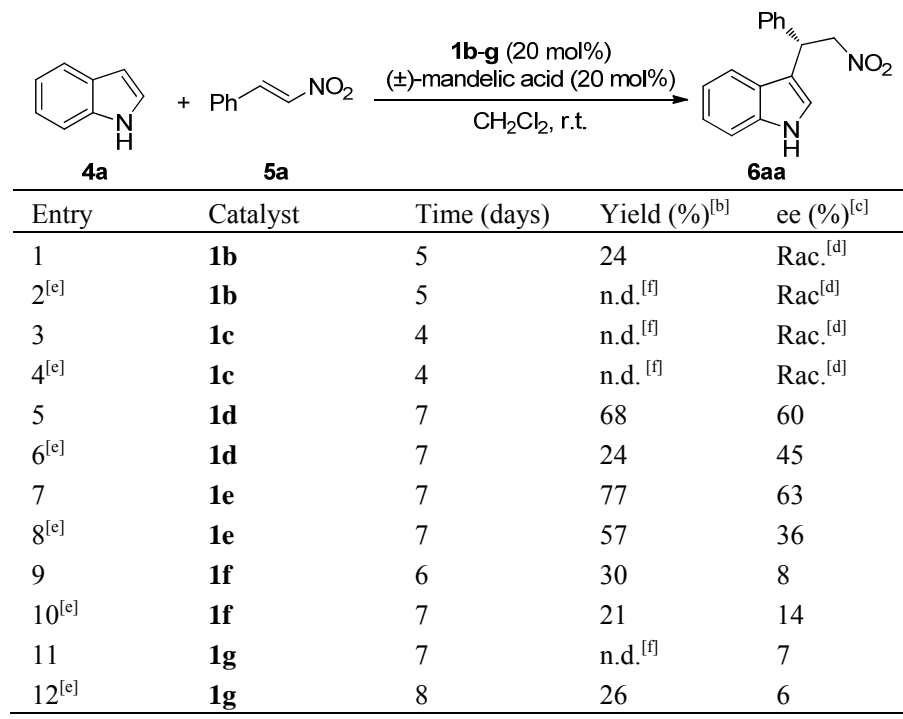

[a] Experimental conditions: To a mixture of catalyst $\mathbf{1 b}-\mathbf{g}(0.02 \mathrm{mmol})$, $( \pm)$-mandelic acid $(0.02 \mathrm{mmol})$ and nitroalkene $5 \mathbf{a}(0.1 \mathrm{mmol})$, first indole 4a $(0.15 \mathrm{mmol})$ and then $\mathrm{CH}_{2} \mathrm{Cl}_{2}(500 \mu \mathrm{L})$ were further added, in a test tube at room temperature. After the reaction time, compound $\mathbf{6 a a}$ was isolated by flash chromatography. [b] Isolated yield. [c] Determined by chiral HPLC analysis (Chiralpak IA, flow hexane $/ \mathrm{PrOH}$ 90:10, $1 \mathrm{~mL} / \mathrm{min}$ ). [d] Racemic mixture. [e] In absence of $( \pm)$-mandelic acid. [f] Not determined.

Although in any case we could not improve the results achieved with 1a·HA, several important aspects can be deduced from these Table 3. Screening of different reaction conditions using $\mathbf{1 a} \cdot \mathbf{H A} .^{[a]}$ results. The presence of $\mathrm{OH}$ group in the skeleton of $\mathbf{1 a}$ with cis configuration seems to be crucial for both enantioselectivity and reactivity as previously reported, ${ }^{[7 \mathrm{a}, 10 \mathrm{c}]}$ since catalysts $\mathbf{1 b}$ and $\mathbf{1 f}$ (entries 1 and 9) and catalysts $\mathbf{1 c}$ and $\mathbf{1 g}$ (entry 3 and 11) afforded poorer results compared with that obtained using catalyst 1a. This fact indicates that even when the presence of $\mathrm{OH}$ in the skeleton is important the hydroxyl group must be placed in the appropriate position, in order to direct efficiently the attack of the external nucleophile, as previously invoked.$^{[7 \mathrm{a}, 10 \mathrm{c}]}$ The electronic effects of $\mathrm{CF}_{3}$ groups in the aromatic ring of thiourea catalyst 1a seem to be also essential for the enantioselectivity, as catalysts $\mathbf{1 d}$ and $\mathbf{1 e}$ bearing different electron-withdrawing groups provided lower enantioinduction (entries 5 and 7). These results allowed the identification of system 1a. HA as the most efficient in terms of enantioselectivity and reactivity. After these results, we decided to continue in the subsequent screening with catalyst 1a and ( \pm )mandelic acid or $\mathrm{CH}_{2} \mathrm{ClCO}_{2} \mathrm{H}$ as additives. To optimize our cooperative catalyst system we also tested other parameters such as solvent, temperature, variation in the concentration and equivalents of acid. On the basis of our experience we realized that solvent polarity might play an important role governing the enantioselectivity of the reaction. In this context, we explored different solvents on the 1a·HA-promoted Friedel-Crafts alkylation process (See Supporting Information). Among the solvents tested, $\mathrm{CHCl}_{3}$ and $\mathrm{CH}_{2} \mathrm{Cl}_{2}$ allowed the obtainment of the higher values of ee. We decided to continue with $\mathrm{CH}_{2} \mathrm{Cl}_{2}$ in the ensuing screening (Table 3 ).

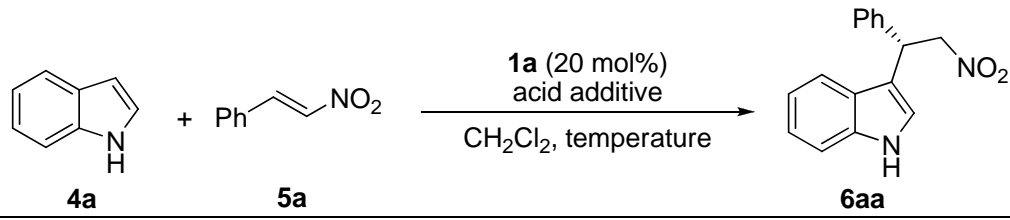

\begin{tabular}{|c|c|c|c|c|c|c|}
\hline & & & & & & \\
\hline Entry & Solvent $(\mu \mathrm{L})$ & Acid (equivalents) $^{[\mathrm{b}]}$ & Temperature $\left({ }^{\circ} \mathrm{C}\right)$ & Time (days) & Yield $(\%)^{[\mathrm{c}]}$ & ee $(\%)^{[\mathrm{d}]}$ \\
\hline 1 & $\mathrm{CH}_{2} \mathrm{Cl}_{2}(500)$ & $( \pm)$-Mandelic acid (1) & 3 & 4 & 59 & 74 \\
\hline 2 & $\mathrm{CH}_{2} \mathrm{Cl}_{2}(500)$ & No acid & 3 & 4 & 21 & 40 \\
\hline 3 & $\mathrm{CH}_{2} \mathrm{Cl}_{2}(500)$ & $( \pm)$-Mandelic acid (1) & -10 & 4 & 32 & 82 \\
\hline 4 & $\mathrm{CH}_{2} \mathrm{Cl}_{2}(500)$ & No acid & -10 & 4 & 24 & 66 \\
\hline 5 & $\mathrm{CH}_{2} \mathrm{Cl}_{2}(100)$ & $( \pm)$-Mandelic acid (1) & -25 & 3 & 61 & 87 \\
\hline 6 & $\mathrm{CH}_{2} \mathrm{Cl}_{2}(250)$ & $\mathrm{CH}_{2} \mathrm{ClCO}_{2} \mathrm{H}$ acid (1) & -25 & 4 & 64 & 84 \\
\hline $7^{[\mathrm{e}]}$ & $\mathrm{CH}_{2} \mathrm{Cl}_{2}(250)$ & $( \pm)$-Mandelic acid (1) & -25 & 4 & 45 & 88 \\
\hline $8^{[\mathrm{e}]}$ & $\mathrm{CH}_{2} \mathrm{Cl}_{2}(250)$ & No acid & -25 & 4 & 34 & 77 \\
\hline 9 & $\mathrm{CH}_{2} \mathrm{Cl}_{2}(250)$ & $( \pm)$-Mandelic acid (1) & -25 & 3 & 63 & 88 \\
\hline 10 & $\mathrm{CH}_{2} \mathrm{Cl}_{2}(250)$ & (L)-Mandelic acid (1) & -25 & 3 & 55 & 88 \\
\hline 11 & $\mathrm{CH}_{2} \mathrm{Cl}_{2}(250)$ & (D)-Mandelic acid (1) & -25 & 3 & 53 & 89 \\
\hline 12 & $\mathrm{CH}_{2} \mathrm{Cl}_{2}(250)$ & No acid & -25 & 3 & 40 & 82 \\
\hline 13 & $\mathrm{CH}_{2} \mathrm{Cl}_{2}(250)$ & $( \pm)$-Mandelic acid (2) & -25 & 3 & 53 & 88 \\
\hline 14 & $\mathrm{CH}_{2} \mathrm{Cl}_{2}(250)$ & (L)-Mandelic acid (2) & -25 & 3 & 56 & 88 \\
\hline 15 & $\mathrm{CH}_{2} \mathrm{Cl}_{2}(250)$ & (D)-Mandelic acid (2) & -25 & 3 & 60 & 89 \\
\hline 16 & $\mathrm{CH}_{2} \mathrm{Cl}_{2}(250)$ & (D)-Mandelic acid (0.5) & -25 & 4 & 55 & 87 \\
\hline 17 & $\mathrm{CH}_{2} \mathrm{Cl}_{2}(250)$ & (D)-Mandelic acid (3) & -25 & 4 & 64 & 87 \\
\hline 18 & $\mathrm{CH}_{2} \mathrm{Cl}_{2}(250)$ & (D)-Mandelic acid (5) & -25 & 4 & 67 & 86 \\
\hline $19^{[\mathrm{f}]}$ & $\mathrm{CH}_{2} \mathrm{Cl}_{2}(250)$ & (D)-Mandelic acid (2) & -25 & 4 & n.r. ${ }^{[\mathrm{g}]}$ & n.r. ${ }^{[\mathrm{g}]}$ \\
\hline
\end{tabular}

[a] Experimental conditions: To a mixture of catalyst 1a $(0.02 \mathrm{mmol})$, acid additive $(0.02 \mathrm{mmol})$ and nitroalkene $5 \mathbf{a}(0.1 \mathrm{mmol})$, first indole $4 \mathbf{4 a}(0.15 \mathrm{mmol})$ and then $\mathrm{CH}_{2} \mathrm{Cl}_{2}$ (the corresponding amount) were further added, in a test tube at the indicated temperature. After the reaction time, compound 6aa was isolated by chromatography. [b] Equivalents of acid respect to catalyst 1a. [c] Isolated yield. [d] Determined by chiral HPLC analysis (Chiralpak IA, flow hexane/iPrOH 90:10, $1 \mathrm{~mL} / \mathrm{min})$. [e] $10 \mathrm{~mol} \%$ of 1a. [f] Reaction performed in absence of catalyst 1a. [g] No reaction observed.

Lowering the reaction temperature from $25{ }^{\circ} \mathrm{C}$ to $-25{ }^{\circ} \mathrm{C}$ we could increase the enantioselectivity up to $89 \%$ (entries 11 and 15) although the reaction rate was decreased. However, additional variations in the concentration and equivalents of acid did not lead 
to improved results. We tested the same reaction in absence of acid for different temperatures and conditions (entries 2, 4, 8 and 12) and in all cases lower values were obtained compared with 1a·HA in terms of enantioselectivity and reactivity. Unfortunately, the high differences achieved at room temperature, between the reaction performed in presence or in absence of acid, are not maintained at low temperature, maybe due to a different mode of coordination between the thiourea catalyst and the acid. We realized that at low temperature the amount of active complex 1a $\cdot \mathbf{H A}$ could be depending on the equivalents and the enantiomeric form used. Comparative experiments performed with $( \pm)-,(\mathrm{L})$ - and (D)-mandelic acid showed identical results, although 2 equivalents of (D)-mandelic acid gave slightly improved results in terms of enantioselectivity and reactivity (entry 15). Interestingly, in absence of catalyst 1a, the reaction does not proceed even after 4 days (entry 19), supporting the fact that the acid is activating the catalyst structure more than one of the reagents.

Finally, with the optimal reaction conditions in hand, we investigated the scope of our protocol using catalyst 1a and (D)mandelic acid in a comparative study performing the reaction also in absence of additive (values in parentheses) (Table 4).

Table 4. Final scope of 1a·HA catalyzed Friedel-Crafts alkylation reaction. ${ }^{[\mathrm{a}]}$

\begin{tabular}{|c|c|c|c|c|c|c|}
\hline & \multirow{2}{*}{\begin{tabular}{l}
\multicolumn{1}{c}{ 5a-g } \\
Nitroalkene \\
$\left(\mathrm{R}^{3}\right)$ \\
\end{tabular}} & \multicolumn{2}{|c|}{$\begin{array}{l}1 \mathrm{a}(20 \mathrm{~mol} \%) \\
\underset{\mathrm{CH}_{2} \mathrm{Cl}_{2},-25^{\circ} \mathrm{C}}{\longrightarrow}\end{array}$} & \multicolumn{2}{|l|}{6} \\
\hline Entry & $\begin{array}{l}\text { Indole } \\
\left(\mathrm{R}^{1}, \mathrm{R}^{2}\right) \\
\end{array}$ & & Product & $\begin{array}{l}\text { Time } \\
\text { (days) }\end{array}$ & $\begin{array}{l}\text { Yield } \\
(\%)^{[b]} \\
\end{array}$ & $\begin{array}{l}\text { ee } \\
(\%)^{[c]}\end{array}$ \\
\hline 1 & 4a $\mathrm{H}, \mathrm{H}$ & 5b $4-\mathrm{MePh}$ & 6ab & 3 & $50(39)$ & $88(62)$ \\
\hline 2 & 4a $\mathrm{H}, \mathrm{H}$ & 5c 4-MeOPh & 6ac & 3 & $45(24)$ & $84(66)$ \\
\hline 3 & 4a $\mathrm{H}, \mathrm{H}$ & 5d 2-furyl & 6ad & 3 & $58(27)$ & $82(68)$ \\
\hline 4 & 4a $\mathrm{H}, \mathrm{H}$ & 5e 4-ClPh & 6ae & 3 & $75(33)$ & $88(75)$ \\
\hline 5 & 4a $\mathrm{H}, \mathrm{H}$ & 5f $4-\mathrm{BrPh}$ & 6af & 3 & $30(17)$ & $87(68)$ \\
\hline 6 & 4a $\mathrm{H}, \mathrm{H}$ & $5 g$ 4-FPh & 6ag & 3 & $67(42)$ & $88(64)$ \\
\hline 7 & $\begin{array}{l}\mathbf{4 b} \\
\mathrm{H}, \mathrm{Me}\end{array}$ & 5a $\mathrm{Ph}$ & 6ba & 4 & 94(91) & $58(52)$ \\
\hline $8^{[\mathrm{d}]}$ & $\mathbf{4 d ~ C l , H}$ & 5a $\mathrm{Ph}$ & 6da & 5 & 25(n.d.) & $86(70)$ \\
\hline 9 & $\mathbf{4 e} \mathrm{F}, \mathrm{H}$ & $5 a \mathrm{Ph}$ & 6ea & 5 & $28(12)$ & $86(72)$ \\
\hline 10 & $\begin{array}{l}\text { 4f } \\
\mathrm{MeO}, \mathrm{H}\end{array}$ & $5 a \mathrm{Ph}$ & $6 f a$ & 4 & $88(74)$ & $86(82)$ \\
\hline
\end{tabular}

[a] Experimental conditions: To a mixture of catalyst 1a $(0.02 \mathrm{mmol})$, (D)mandelic acid $(0.04 \mathrm{mmol})$ and nitroalkene $5 \mathrm{a}-\mathrm{g}(0.1 \mathrm{mmol})$, first indole 4a-f $(0.15 \mathrm{mmol})$ and then $\mathrm{CH}_{2} \mathrm{Cl}_{2}(0.25 \mathrm{~mL})$ were further added, in a test tube at low temperature $\left(-25^{\circ} \mathrm{C}\right)$. After the reaction time, products 6 were isolated by flash chromatography. [b] Isolated yield. [c] Determined by chiral HPLC analysis (see Supporting Information). [d] $100 \mu \mathrm{L}$ of solvent.

The reactions were stopped, even when they were not complete, after a reasonable number of days in order to compare the results with 1a.HA with those obtained with the sole catalyst 1a. The procedure was successfully extended to different substituted nitroalkenes 5a-g and indoles 4a-f furnishing the corresponding adducts $\mathbf{6}$ in useful yields and very good enantioselectivities, as summarized in Table 4. Although in a few cases just slightly higher values are achieved in comparison with the reaction in absence of acid (entries 7 and 10), in general the presence of acid renders better results in terms of both reactivity and enantioselectivities. Aromatic and heteroaromatic nitroolefins with electronwithdrawing and electron-donating groups reacted well with indole to afford alkylated adducts 6ab-ag with good yields and high enantioselectivities (entries 1-6). Even though nitrostyrenes containing electron-donating groups show a slightly lower reaction

rate than the reaction of nitrostyrenes containing an electronwithdrawing group (compare entries 1-3 vs entries 4 and 6, except using 4-Br (entry 5)), the enantioselectivity was independent of the substituent in the aromatic ring. The electronic effect on the indole ring was also considered (entries 7-10). In this sense when a $\mathrm{Me}$ group was introduced in the 2-position of the indole structure, the enantioselectivity dropped although the reactivity was higher (entry 7). On the other hand, electron-withdrawing groups in the 5position of the indole did not affect the enantionselectivity of the process, but the reaction rate was dramatically lower compared with indoles bearing electron-donating groups (entries 8 and $9 v s$ and 10). The absolute configuration of adducts 6 was assigned by comparison of their optical rotation with those reported in the literature for the same products. ${ }^{[7]}$

Some authors have previously proposed the active complexes $\mathbf{I}^{[15 \mathrm{~b}-\mathrm{d}, 16]}$ and $\mathbf{I I} \mathbf{I}^{[15 \mathrm{a}]}$ depicted in Figure 4 , as suitable modes of interaction between an acid catalyst and a thiourea additive in the transition state. Although at this stage we cannot ensure the role of the acid in our mechanism, according to the experimental results we believe that in this reaction the mode of activation could be different to those previously invoked. Firstly, if III was the mode of activation in our mechanism, the chirality of the acid would influence which of the enantiomers is obtained, more than the catalyst chirality. Different signs and values of enantioselectivity should be expected using (D)-, (L)- or ( \pm )-mandelic acid as additives, but it is not the case. Moreover, III would not be in agreement with the good results obtained with $(R)$ $\mathrm{PhCH}(\mathrm{OMe}) \mathrm{CO}_{2} \mathrm{H}$ (Table 1 , entry 3 ). On the basis of all these results we consider that the activation of the thiourea moiety with the acid (IV) in an upper face might explain better our outcomes, although more experiments are necessaries to clarify this mode of action. From the experimental results we can assume that the catalytic complex 1a·HA is a more reactive species, maybe due to lower thiourea's $p \mathrm{~K}_{\mathrm{a}}$, therefore increasing the reaction rate. It is also remarkable the stronger union between both species, clearly more favored against the independently activation of each one with the substrates. Furthermore, the improvement of the enantioselectivity could be explained by generating a more rigid assembly in the transition state, as a combination of both structures.<smiles>O=C(OCN(C(=S)Nc1cc(C(F)(F)F)cc(C(F)(F)F)c1)c1cc(C(F)(F)F)cc(C(F)(F)F)c1)C1CCCN1</smiles>

I

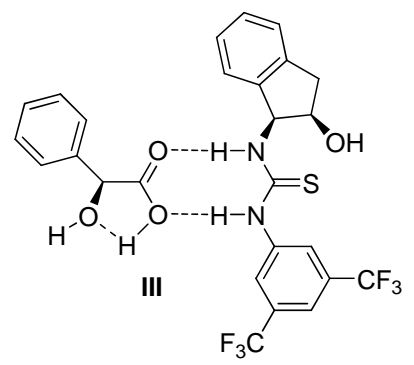

Figure 4. Hydrogen-bonding mediated cooperative catalysis.
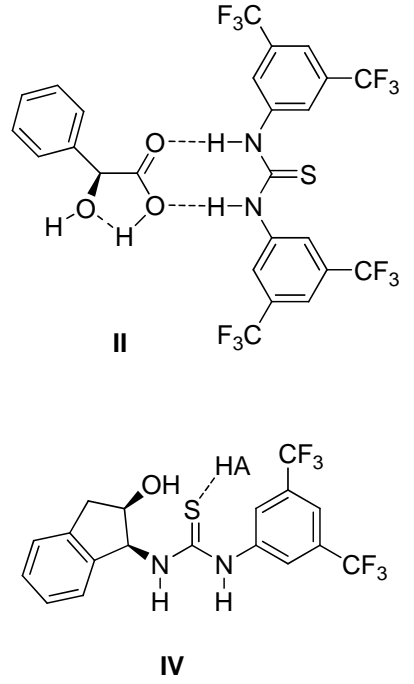

IV 
However, we cannot discard the possible simultaneous coordination of the acid and the thiourea moiety to one of the reagents involved in our reaction, as proposed by Shi and coworkers. ${ }^{[17]}$ Additional computational calculations and NMR experiments ${ }^{[18]}$ are being performed in order to shed light to this interesting and novel reactivity and they will be published in due course.

\section{Conclusions}

The results show the property of a Brønsted acid-assisted thiourea catalyst rendering a more effective catalyst complex for the enantioselective Friedel-Crafts reaction of indoles with nitroalkenes. The synergic effect between both species is higher than the effect promoted by each one separately. The easy modulation of the acid nature allows the convenient alteration of the chiral environment and the $p \mathrm{~K}_{\mathrm{a}}$ of the donor hydrogen, in our case the thiourea catalyst 1a. These results could open a new interesting line of research related with the effect of additives in thiourea catalyzed reactions, concept scarcely considered so far in the literature. Moreover, this contribution could become an important starting point for further investigations. Additional studies to clarify our plausible mechanistic hypothesis by NMR experiments and computational calculations, as well as, its following application to other enantioselective thiourea catalyzed systems, are in progress in our laboratories.

\section{Experimental Section}

\section{General Information}

Purification of reaction products was carried out by flash chromatography using silical-gel $(0.063-0.200 \mathrm{~mm})$ or medium pressure liquid chromatography using prepacked silica columns. Analytical thin layer chromatography was performed on $0.25 \mathrm{~mm}$ silical gel $60-\mathrm{F}$ plates. ${ }^{1} \mathrm{H}$ NMR spectra were recorded at $400 \mathrm{MHz}$ and ${ }^{13} \mathrm{C}$ NMR spectra were recorded at $100 \mathrm{MHz}$, using $\mathrm{CDCl}_{3}$ as solvent. Chemical shifts were reported in the $\delta$ scale relative to residual $\mathrm{CHCl}_{3}\left(7.26 \mathrm{ppm}\right.$ for ${ }^{1} \mathrm{H}$ NMR and $77.0 \mathrm{ppm}$ for ${ }^{13} \mathrm{C}$ NMR.

Materials. All commercially available solvents and reagents were used as received. $\mathrm{CH}_{2} \mathrm{Cl}_{2}$ was filtered through basic alumina prior to use to avoid the presence of traces of acid. Chiral thioureas catalysts were obtained following the literature procedure: $\mathbf{1 a},{ }^{[10 c]} \mathbf{1 b},{ }^{[10 c]} \mathbf{1} \mathbf{c}^{[19]}$ and $\mathbf{1 f}{ }^{[7 c]}$ Starting materials, yields and spectroscopic data for compounds 1d, 1e, $1 \mathbf{g}$ and $\mathbf{6 e a}$ are described in the Supporting Information. ${ }^{1} \mathrm{H}$ and ${ }^{13} \mathrm{C}$ NMR spectra for compounds $6 \mathbf{6 a},{ }^{[7 a]} \mathbf{6 a b}-6 a f,{ }^{[7 \mathrm{dd}} \mathbf{6 a g},{ }^{[20]}$ and $\mathbf{6 b a}-\mathbf{d a}, \mathbf{f a}^{[7 \mathrm{ad}]}$ are consistent with values previously reported in the literature.

General procedure for 1a-HA catalyzed Friedel-Crafts alkylation reaction: To a mixture of catalyst $1 \mathbf{1 a}(20 \mathrm{~mol} \%)$, (D)-mandelic acid (40 $\mathrm{mol} \%)$ and nitroalkene $5 \mathbf{a}-\mathrm{g}(0.1 \mathrm{mmol})$ at low temperature $\left(-25^{\circ} \mathrm{C}\right)$, first indole 4a-f $(0.15 \mathrm{mmol})$ and then $\mathrm{CH}_{2} \mathrm{Cl}_{2}(0.25 \mathrm{~mL})$ are further added, in a test tube. After the appropriate reaction time (see Table 4), the residue was purified by flash chromatography or medium pressure liquid chromatography $\left(\mathrm{SiO}_{2}\right.$, hexane/EtOAc 8:2) to afford final adducts 6. Yields and enantioselectivities are reported in Table 4 . Spectral and analytical data for compounds 6 are in agreement with those previously reported in the literature. The HPLC chromatograms for final adducts are reported in the Supporting Information.

Supporting Information (see footnote on the first page of this article): Detailed experimental procedures and characterization data for compounds 1d, 1e, 1g and 6ea and HPLC chromatograms for all final products are presented.

\section{Acknowledgments}

We thank the Ministry of Science and Innovation (MICINN. Madrid. Spain. Project CTQ2010-19606) and the Government of Aragón (Zaragoza. Spain. Project PI064/09 and Research Groups, E-10) for financial support of our research. We are also grateful to Prof. Luca Bernardi for useful comments. E. M.-L. thanks CSIC for a JAE-Doc postdoctoral contract. R. P. H. thanks the Aragón I+D Foundation for her permanent position.

[1] C. Friedel, J. M. Crafts, C. R. Hebd. Seances Acad. Sci. 1877, 84, $1392-1395$.

[2] For reviews on Friedel-Crafts metal catalyzed alkylation reactions, see: a) K. A. Jørgensen, Synthesis 2003, 1117-1125; b) M. Bandini, A. Melloni, A. Umani-Ronchi, Angew. Chem. Int. Ed. 2004, 43, 550556; c) M. Bandini, A. Melloni, S. Tommasi, A. Umani-Ronchi, Synlett 2005, 1199-1222; d) T. B. Poulsen, K. A. Jørgensen, Chem Rev. 2008, 108, 2903-2915; e) Catalytic Asymmetric Friedel-Crafts Alkylations, (Eds.: M. Bandini, A. Umani-Ronchi), Wiley-VCH Weinheim, 2009.

[3] For reviews on Friedel-Crafts organocatalyzed alkylation reactions, see: a) E. Marqués-López, A. Diez-Martinez, P. Merino, R. P. Herrera, Curr. Org. Chem. 2009, 13, 1585-1609; b) S.-L. You, Q. Cai, M. Zeng, Chem. Soc. Rev. 2009, 38, 2190-2210; c) V Terrasson, R. M. de Figueiredo, J. M. Campagne, Eur. J. Org. Chem. 2010, 2635-2655; d) M. Zeng, S.-L. You, Synlett 2010, 1289-1301.

[4] a) Friedel-Crafts and Related Reactions, (Ed.: G. A. Olah), WileyInterscience, New York, 1963; vols. 1-4; b) Friedel-Crafts Chemistry, (Ed.: G. A. Olah), Wiley, New York, 1973; c) R. M. A. Roberts, A. Khalaf in Friedel-Crafts Alkylation Chemistry a Century of Discovery, Marcel Dekker: New York, 1984; c) Indoles, (Ed.: R. J. Sundberg), Academic Press: London, 1996; d) Pharmaceutical Substances, (Eds.: A. Kleeman, J. Engel, B. Kutscher, D. Reichert), Thieme: New York, 2001; e) H.-J. Borschberg, Curr. Org. Chem. 2005, 9, 1465-1491; f) S. Cacchi, G. Fabrizi, Chem. Rev. 2005, 105, 2873-2920.

[5] O. M. Berner, L. Tedeschi, D. Enders, Eur. J. Org. Chem. 2002, 1877-1894.

[6] a) The Nitro Group in Organic Synthesis, (Ed.: N. Ono), Wiley-VCH, New York, 2001; b) R. Ballini, M. Petrini, Tetrahedron 2004, 60, 1017-1047.

[7] For scarce examples, see: a) R. P. Herrera, V. Sgarzani, L. Bernardi, A. Ricci, Angew. Chem. Int. Ed. 2005, 44, 6576-6579; b) W. Zhuang, R. G. Hazell, K. A. Jørgensen, Org. Biomol. Chem. 2005, 3, 25662571 ; c) E. M. Fleming, T. McCabe, S. J. Connon, Tetrahedron Lett. 2006, 47, 7037-7042; d) M. Ganesh, D. Seidel, J. Am. Chem. Soc 2008, 130, 16464-16465; e) J. Itoh, K. Fuchibe, T. Akiyama, Angew. Chem. Int. Ed. 2008, 47, 4016-4018; f) Y.-F. Sheng, G.-Q. Li, Q Kang, A.-J. Zhang, S.-L. You, Chem. Eur. J. 2009, 15, 3351-3354 g) Y.-F. Sheng, Q. Gu, A.-J. Zhang, S.-L. You, J. Org. Chem. 2009, 74, 6899-6901; h) Y. Sohtome, B. Shin, N. Horitsugi, R. Takagi, K Noguchi, K. Nagasawa, Angew. Chem. Int. Ed. 2010, 49, 7299-7303; i) N. Takenaka, J. Chen, B. Captain, R. S. Sarangthem, A. Chandrakumar, J. Am. Chem. Soc. 2010, 132, 4536-4537; j) T Hirata, M. Yamanaka, Chem. Asian J. 2011, 6, 510-516.

[8] For non-chiral organocatalyzed examples, see: a) G. Dessole, R. P. Herrera, A. Ricci, Synlett 2004, 2374-2378; b) L.-T. An, J.-P. Zou, L.-L. Zhang, Y. Zhang, Tetrahedron Lett. 2007, 48, 4297-4300.

[9] a) P. R. Schreiner, Chem. Soc. Rev. 2003, 32, 289-296; b) Y. Takemoto, Org. Biomol. Chem. 2005, 3, 4299-4306; c) S. J. Connon, Chem. Eur. J. 2006, 12, 5418-5427; d) M. S. Taylor, E. N. Jacobsen, Angew. Chem. Int. Ed. 2006, 45, 1520-1543; e) A. G. Doyle, E. N. Jacobsen, Chem. Rev. 2007, 107, 5713-5743; f) Z. Zhang, P. R. Schreiner, Chem. Soc. Rev. 2009, 38, 1187-1198; g) E. MarquésLópez, R. P. Herrera, An. Quim. 2009, 105, 5-12; h) M. Kotke, P. R. Schreiner in Hydrogen Bonding in Organic Synthesis, (Ed.: P. M. Pihko), Wiley-VCH: Weinheim, 2009, pp 141-351.

[10] a) D. Pettersen, R. P. Herrera, L. Bernardi, F. Fini, V. Sgarzani, R. Fernández, J. M. Lassaletta, A. Ricci, Synlett 2006, 239-242; b) L. Bernardi, F. Fini, R. P. Herrera, A. Ricci, V. Sgarzani, Tetrahedron 2006, 62, 375-380; c) R. P. Herrera, D. Monge, E. Martín-Zamora, R. Fernández, J. M. Lassaletta, Org. Lett. 2007, 9, 3303-3306; d) A. Alcaine, E. Marqués-López, P. Merino, T. Tejero, R. P. Herrera, Org. Biomol. Chem. 2011, 9, 2777-2783.

[11] K. H. Jensen, M. S. Sigman, Angew. Chem. Int. Ed. 2007, 46, 47484750.

[12] a) M. T. Robak, M. Trincado, J. A. Ellman, J. Am. Chem. Soc. 2007, 129, 15110-15111; b) S. S. So, J. A. Burkett, A. E. Mattson, Org Lett. 2011, 13, 716-719. 
[13] For a review of combined acid catalysis, see: H. Yamamoto, K. Futatsugi, Angew. Chem. Int. Ed. 2005, 44, 1924-1942.

[14] E. Marqués-López, R. P. Herrera, Curr. Org. Chem. 2011 in press.

[15] a) T. Weil, M. Kotke, C. M. Kleiner, P. R. Schreiner, Org. Lett. 2008, 10, 1513-1516; b) X. Companyó, G. Valero, L. Crovetto, A. Moyano, R. Rios, Chem. Eur. J. 2009, 15, 6564-6568; c) Ö. Reis, S. Eymur, B. Reis, A. S. Demir, Chem. Commun. 2009, 1088-1090; d) N. El-Hamdouni, X. Companyó, R. Rios, A. Moyano, Chem. Eur. J. 2010, 16, 1142-1148; e) R. S. Klausen, E. N. Jacobsen, Org. Lett. 2009, 11, 887-890; f) H. Xu, S. J. Zuend, M. G. Woll, Y. Tao, E. N. Jacobsen, Science 2010, 327, 986-990.

[16] For the same mode of activation using urea catalyst, see: S. L. Poe, A. R. Bogdan, B. P. Mason, J. L. Steinbacher, S. M. Opalka, D. T McQuade, J. Org. Chem. 2009, 74, 1574-1580.

[17] Y.-L. Shi, M. Shi, Adv. Synth. Catal. 2007, 349, 2129-2135.

[18] See supporting information for a preliminary NMR experiment.

[19] C. Gioia, L. Bernardi, A. Ricci, Synthesis 2010, 161-170.

[20] Y.-X. Jia, S.-F. Zhu, Y. Yang, Q.-L. Zhou, J. Org. Chem. 2006, 71, $75-80$. 